\title{
The Effects of Embedding Information Technologies within ELT on EFL Learners' Motivation and Interest
}

\author{
Shaker Al-Mohammadi (Corresponding author) \\ Buraimi University College, Oman \\ University of Manouba, Tunisia \\ Po Box 77. Postal Code 512 Buraimi City, Oman \\ Tel: 0096896282473 E-mail: shaker@buc.edu.om \\ Emira Derbel \\ Buraimi University College \\ Po Box 77. Postal Code 512 Buraimi City, Oman \\ Tel: 0096896649513 E-mail: emira@buc.edu.om
}

Received: 02-10-2013

doi:10.7575/aiac.ijalel.v.3n.1p.181
Accepted: 11-11-2013

URL: http://dx.doi.org/10.7575/aiac.ijalel.v.3n.1p.181

\begin{abstract}
In today's globalised world, technologies have been embedded in every aspect of daily activities and discourses. The field of education made no exception and hence technologies have become an integral part of all educational systems worldwide, but with different levels and layers. The presence of information technology in English language teaching has brought about notable changes for teachers and learners alike. Accordingly, this paper investigates the impact of integrating information technologies in ELT on EFL learners' motivation and interest. Based on an authentic comparative case study, this paper explores the influence of information technology on EFL learners' perceptions, motivation, and interest in the context of ELT in the Tunisian higher education. The findings of this study suggest that the integration of IT in ELT heavily affects EFL students' motivation and academic performance and hence EFL instructors should take this variable into consideration.
\end{abstract}

Keywords: ELT, information technology, integration, motivation

\section{Introduction}

From the last century to the present context, the world has witnessed the powerful impact of the technological developments. They have been one of the major factors that brought change in behaviour and attitude of the people. With the growing pace of globalisation affecting all facets of human life, information technologies have become very influential in the modern era. This context paved the way for technologies to infiltrate into almost all aspects of human lives (Bruce \& Hogan, 1998). Education made no exception as information technologies have started to be an integral part of this field nowadays.

One of the sub-fields of education which has been witnessing a noticeable integration of technologies is Language teaching. In fact, embedding information technology within language teaching is not a completely new phenomenon since this integration has been used since the 1960s (Lee, 2000). Warschaue and Whittaker (1997) argue that "these 50 years witness three main stages which are: behaviorist CALL, communicative CALL, and integrative CALL". Hence, the presence of technologies in education is not a novelty, but each of these three stages is associated with a definite level of technology innovation as well as specific pedagogical theories.

The presence of information technology in English language teaching has brought about notable changes for teachers and learners alike (Kuang-wu, 2000). According to Lewis (2009), the technological advances compelled language teachers as well as learners to acquire and enhance new skills and abilities in order to cope with the new context. Nowadays, the strong connection between technology and language use has motivated numerous language teachers, researchers and experts to reflect how technology has been changing the profession of English language teaching around the globe (Chapelle, 2003).

Additionally, the integration of information technology into English language teaching has been under continuous investigation (Hamdy, 2007). An extensive current amount of research is being done on embedding technology with EFL teaching/learning in various Western countries. Nevertheless, this area of research is under-researched in the Arab region, and mainly in Tunisia (Melliti, 2008). It is this gap which lies behind conducting this research which seeks to investigate the impact of information technology innovations on Tunisian EFL learners. Based on an authentic comparative case study that investigates two different groups in a Tunisian higher education institution, this research 
purports to explore the influence of information technology on Tunisian EFL learners' perceptions, motivation, and academic performance in the context of ELT in the Tunisian higher education.

Accordingly this paper tries to answer the following research questions:

(1) What are the EFL learners' perceptions towards embedding information technology within Language teaching?

(2) How does information technology affect EFL Learners' motivation and interest in the program courses?

(3) How is information technology integrated in ELT classes in the context of Tunisian higher education?

\section{Methodology}

The focus of this study is on the effects of Information Technology in relation to language teaching and learning and students' perceptions at the Tunisian higher educational institutions. To reach the aim of this investigation, one major higher education institution was chosen to the site of this research. Situated in the capital of Tunisia, this institution was established in 1986 and it is one of the largest universities in Tunisia with more than 13.000 students up to the academic year of 2012/2013. The University offers various majors at the Bachelor, Master, PhD, and Post-PhD.

\subsection{Importance and Rationale of the study}

Since English is considered to be the first international language the most important language in the world today, then it is of interest to explore how it is valued by users all over the world. Research on English and how it is valued can be tackled from many angles. This research focuses on the issues related to how English is perceived by EFL university students in Tunisia. It mainly investigates the effects of embedding information technologies on EFL teaching and learning. The rationale behind choosing this topic is mainly linked to the functions that English language and technological advances fulfill in Tunisian society. Technology has been affecting all aspects of human life and latest technological developments are instantly occurring. Within this context, the issues related to the use of information technologies and its effects on the field of education in the world and in Tunisia specifically are to be investigated.

In fact, English is generally considered by policy makers in Tunisia advantageous for fulfilling an important role in creating and sustaining links with the world in terms of knowledge and transfer of technology (Derbel, 2001). Accordingly, it is worthy to explore the views of the Tunisian EFL learners regarding the latest strategies and methodologies related to the teaching and learning of English language. Regarding the use of English in the Tunisian society, there is observable evidence of heavy domination of French over English and to some extent over Arabic in the use of electronic devices and in communication with foreigners. However, English has become more present in the lives of Tunisians due to technology, social networking websites and international media that are increasingly available. This paper seeks to empirically investigate the effects of importing the use of information technologies into EFL classrooms. Therefore, the overall motive for conducting this study is to investigate the EFL students' motivational level and interest when they are exposed to EFL classes that embed information technologies. Hence, the findings of this research can be beneficial in suggesting some recommendations for implementation in the context of English Language teaching.

\subsection{Participants}

The participants in this study consist of 60 students enrolled in one higher education institution and divided in two groups $(\mathrm{A}$ and $\mathrm{B} ; \mathrm{A}=30, \mathrm{~B}=30 . \mathrm{N}$ total $=60$ ). They are selected from two different classes and they are both English language majors who are potential teachers of English language. The two groups are taught by many teachers, but for the sake of practicality two definite teachers. were selected: the first teacher is a tech-savvy who is known to be a strong advocate of integrating technology in language teaching and learning; the second teacher belongs to the traditional group who never uses any technological tools in his classes and who prefers the lecturing style of teaching. The participants of the two groups are in their 3rd year (semester six) which was meant to guarantee an acceptable level of maturity in responding to the survey questions. The rationale behind choosing two different groups with a discrepancy in information technology use in their classes is to show the effects of each condition on EFL students' perceptions, motivation, and academic performance.

The investigator is a Tunisian native who has a background in English language learning and teaching at Tunisian higher education institutions during the period from 1998 to 2008. Yet, this background does not influence the researcher's objectivity at any step in conducting this study

\subsection{Research Design and Data Collection}

Participants are Tunisian EFL university students at one major Tunisian university located in the capital of the country. This selection is convenient for this current comparative study to be conducted in a higher educational environment open to researchers and with a large variety of sample EFL learners who can effectively answer survey questions in English language. Participants were asked to take a survey entitled "Perceptions toward Information Technology". In this survey, participants responded to questions about their perceptions toward information technology and its integration within language teaching. This survey included a section that contained the background information of the participants, which means their age, gender, department, and specialization (major and minor). It also aimed at collecting data about the proficiency of the students as they claimed it. Besides, the other sections of this survey tackled the general background of the participants regarding the field of IT, their skills in using the latest technological tools, the status of IT resources in the areas where they live, and the frequency in using IT resources in their daily lives as well as in their studies. 
In addition, participants took a second survey entitled "Course Interests Survey", where they rate their level of interest in the subjects being taught by their respective instructors. The subjects that were suggested to the participants were taught by various teachers who employ different methodologies and teaching techniques. Some teachers were known for embedding information technologies within their EFL classes and some other teachers were used to the traditional teaching methods and the lecturing style. The participants rated their level of interest from level one to level five where level 1 stands for "not interested at all" and level 5 stands for "very interested".

The first selected group was taught in a way where the instructor used varied information technology tools such as videos, PowerPoint slides, online resources, and mobile dictionaries. The second group was taught by another instructor without using information technology resources. Lesson objectives and students learning outcomes were identical for both groups, whereas the medium was different; a technology-based medium in the first group and a traditional medium based on lectures and handouts in the second group.

Both groups took a third survey entitled "Motivation Survey" where they were asked to rate their motivation level toward the materials and the techniques being used for classroom instructions and activities. The participants were given five options that vary from level 1, "not motivated at all", to level 5, "very motivated". Additionally, the participants were given the option of explaining the reasons behind their low or high levels of motivation. This alternative was meant to see if the use of information technologies had any link with the motivational levels of the participants.

The other sources of data that were utilized by the investigator in this study were observations of samples of EFL classes in the university under study in addition to interviews and open discussions with the two teachers. These two additional instruments of data collection were very useful in giving the investigator the opportunity to gather information, observe situations, and reach conclusions based on authentic practice, real context, and genuine teaching and learning atmosphere. Actually, the class visits allowed for a close investigation of the variables being measured in relation to embedding information technologies within EFL classes. Furthermore, the interviews with the two teachers, known for applying different teaching techniques, were very informative regarding the topic under study and the general situation of the EFL learners belonging to the university where the study took place.

An extensive amount of time and resources with different research methods are needed to investigate many issues related to English language teaching in the Tunisian higher educational context. For this study, a mixed method case study approach that employs survey questionnaires, interviews, class observations, and open discussions is the most practical method to investigate the effect of information technologies on Tunisian EFL learners. The variables that are measured and investigated include attitudes and perceptions, academic performance, motivational level, and interest.

\subsection{Data Analysis}

Once all the data were ready, they were imported into SPSS worksheets where the various analyses were run to create reports and to determine significance of the obtained differences. The analysis of the data focused first on the students' perceptions toward information technology based on the "Perceptions toward information technology" survey. In this section of data analysis, it was decided to go through the whole participants and not the two groups separately. Next, the analysis undertook the interest of the students in the subject based on the data collected through the "Course Interest Survey". Here also, the investigator preferred to look at the participants as a whole rather than considering the two groups separately. This decision was due to the fact that all the 60 participants are majoring in English language and they all study the same identical courses at the same university. The third phase, the analysis tackled the data collected through the "Motivation Survey" to investigate the motivation levels of the students. Here, the participants were considered separately according to the two groups for the sake of determining the effects of IT on students' motivation.

\section{Background to the Study}

\subsection{ELT in Tunisian Secondary Schools: From the Audio-Lingual Method to the Eclectic Approach}

The Tunisian educational system at the Ministry of Education is divided into three main stages: primary education for six years, three years of basic education, and four years of secondary education. Throughout the primary and basic education, the medium of teaching is Modern Standard Arabic, except for French, the second language in Tunisia, which is introduced at the third year of primary education. When students reach the sixth year of primary school, they begin to learn English, which is taught from the last year of primary school to the last year of secondary school. Contrary to the primary and basic school, where most classes are taught in Modern Standard Arabic, in the secondary education most of the math and science classes are taught in French. Only language (Arabic) and liberal arts classes (History, Philosophy, Geography, etc...) are taught in Arabic. English is taught as a foreign language and it is rarely used outside of English language classrooms, as French is the commonly used in everyday life.

The audio-lingual method has influenced policy decisions and pedagogy in Tunisia for a long time (Anggraeni, 2007; Daoud, 1996, p. 600). The influence of the audio-lingual method is influential in the primary and secondary schools, which provide the pedagogical foundation for language teaching. The educational system at the primary and secondary school is centrally controlled by the Tunisian Ministry of Education. Hence, education policies, including teaching methods, are also passed down by the decision makers at the Ministry of Education. These policies change very slowly. In addition, even when government policies and approved education methods change, teachers are slow to implement these changes, preferring to continue to use their own methods. Thus, teachers have often used the audio-lingual method in their teaching through nine years of primary and basic school education and four years of secondary school education. Therefore, these students are accustomed to this method when they start to learn English in the sixth year of 
primary school. Students finish their secondary school education by taking a national general secondary education exam called the "Tunisian Baccalaureate". Passing this national exam is an obligatory university entrance requirement for all Tunisian students.

Throughout the different phases of EFL teaching in Tunisia different approaches have been implemented. Since, each approach has its own strengths and weaknesses, the decision makers responsible for English Language teaching in Tunisia have decided to resort to a "principled eclecticism" that integrates many principles from various approaches in language teaching. Therefore, it can be said that English language supervisors and text books authors have distanced themselves from using any one method.

\subsection{English Language Learning at Universities in Tunisia}

After the country gained independence from France in 1956, education in Tunisia has witnessed rapid developments. Ever since, education has become one of the main concerns of the government as well as the society at large. Gradually it became compulsory and free for all children with no segregated schools based on gender. Currently, there are about 239 higher educational institutions in Tunisia including private and public. These institutions accommodate more than 500.000 university students (Ministry oh Higher Education, 2008).

Once secondary school students pass the General Secondary School Education exam, known as the "Baccalaureate", they can elect to continue their studies in the university. Many of the students who enroll in the university system study English. All university campuses and schools of higher education are under the authority of the Ministry of Higher Education and Scientific Research. This ministry approves all post-secondary programs and courses. Most liberal arts subjects, such as languages, are taught at campuses that are designated as liberal arts campuses. These liberal arts campuses, along with higher education language schools, teach English as a university major. In all other universities offering other majors, English is a compulsory course. These English courses vary from general English to English for specific purposes that match with the majors offered. All university campuses and schools of higher education generally have the same academic system, because the academic program is decided by the Ministry of Higher Education (Ministry of Higher Education, 2008).

In 2006, the government made one major educational reform by introducing a new system called LMD, which stands for "License" (Bachelor) "Mastere" (Master's), "Doctorat" (Ph.D.) with a specific time completion guidelines; 3 years for Bachelor, 2 years for Masters and 3 to 5 years for Ph.D. The LMD regulations came with the credit hours system and changed the 4 years programs to compressed 3 years of study programs. This system received harsh criticism from many parties including teachers, supervisors, experts and stakeholders. Recently, there have been serious thoughts towards the revision or abolishment for this system.

\section{Findings and Discussion}

Data analysis is drawn from the surveys explained previously. The findings are organized by the surveys, then, by research questions based on the interpretation of the data.

\subsection{Findings of Survey 1: Students' Perceptions toward Information Technology}

Data collected from this survey show that participants in both groups share positive perceptions toward information technology and its embedding within language teaching. The first section of the survey is related to broad questions to explore the technology culture of the participants. Around $75 \%$ of the participants had access to computers at home while less than $10 \%$ use laptops in class. More than $70 \%$ of the participants stated that they have access to the internet at home but none reported that s/he has access to the internet on campus, despite the fact that $4 \mathrm{G}$ networks in Tunisia are available at reasonable prices. Having no wireless access to the internet at the university campus is the main reason behind the lack of this web access.

Answering questions about their experience with using computers, around $60 \%$ of the participants reported that they use computers at home for learning purposes. $40.4 \%$ use computers daily, $24 \%$ use computers weekly, and $35.6 \%$ use computers occasionally. The vast majority of the participants affirmed that they did not have formal IT training, thus, most participants acquired technology skill through their own.

\subsection{Findings of Survey 2. Course Interest Survey}

Generally, this survey revealed high scores of course interest from the two groups. This indicates that the participants have a high interest in the subject; especially that it was their own decision to major in English language. A comparison between the two groups' scores showed that both groups had almost the same level. This comparison revealed a slight difference between the two groups' score which is calculated as non-significant.

\subsection{Findings of Survey 3: Motivation}

The analysis of the data collected from this survey aimed at looking for differences in terms of motivational level among the two groups. The participants from the technology group reported higher motivational level compared to the non-technology group. $90 \%$ of the technology group reported that their classes which integrate IT in English language teaching is very motivating and $10 \%$ stated that it is motivating whereas no single student mentioned that it was not motivating. Contrary to this finding, $79 \%$ of the non-technology group reported that their EFL classes are not motivating at all, $16 \%$ stated that they are not motivating, and only $5 \%$ stated that the lectures were motivating. Accordingly, the difference between the technology group and the non-technology group in terms of motivational level is significant. 


\subsection{The Teachers' Voices: Interviews}

The first interview with the instructor of the technology group revealed valuable insights and opinions. He stated that even in terms of class participation, projects submission, exam grades and overall academic performance students who are exposed to, and active in, using information technology in their studies on campus and outside it are much better than their peers. Also, he claimed that the traditional way of teaching which relies on the lecturing style using textbooks and handouts does not motivate students nowadays as computer-assisted learning does.

In replying to a follow up question about what can be predicted about the future prospects of IT presence in EFL teaching and learning in the Tunisian higher educational context, the teacher said that using IT in teaching EFL and preparing future EFL teachers has made a huge impact on his students. He predicted that IT is gradually spreading in ELT and very soon teachers who are not "tech savvy" and who do not use IT tools in their classes will be outdated.

In the second interview with the teacher of the non-technology group the interviewee mentioned that it depends on the teachers who have different opinions and approaches in designing their materials and selecting their techniques. Some teachers use textbooks. Others use a collection of articles as a textbook. Some others create their own learning materials. He claims that multimedia materials and IT based media are good and beneficial, yet, students always need text based documents and materials that they can use to get prepared for exams during the preparation period.

He also noted that the university where the study took place is a low technology learning context where even primary levels of technology set up require complete independence of the teacher since the number of IT technicians is very low and some of the rooms are not equipped with basic IT tools. Actually, the teacher stated that the lack of IT resources, the lack of support and training, in addition to the routine of bureaucracy are making attempts of IT integration hard and not easily doable. According to him, these obstacles do not encourage teachers to use IT tools in their EFL classes.

\section{Answering the Research Questions}

\subsection{What are the EFL learners' perceptions towards embedding information technology within Language teaching?}

Starting from the survey of perceptions toward information technology, the findings of this study reveal that students in the university under the scope of the study have positive attitudes and perceptions toward information technology and its embedding in language teaching. Tunisian students at this university have a high level of technology literacy. Additionally, students reported that information technology integration in higher education should be enhanced and expanded, as it is considered to be a major source of a great benefit not only for EFL learners, but also for all students from different majors.

\subsection{How does information technology affect EFL Learners' motivation and interest in the program courses?}

The findings of this study suggest that information technology has greatly affected the process of language teaching and learning. But, not all teachers in Tunisian higher education institutions, even in the same institution as is the case study of this research, are integrating IT in their teaching due to various reasons that are beyond the scope of this research. The interview with the first instructor reveals that students' who are frequently exposed to IT tools have better academic achievements than their peers.

Furthermore, though the findings of the "Courses Interest Survey" do not reveal any low level of students' interest in majoring in English language since it was their own decision, it is obvious that embedding information technologies with language teaching has a great effect on EFL learners' motivation. While the technology group showed high level of motivation toward the materials, the lectures, and the instructor's instructions, the non-technology group expressed considerably lower motivational level toward the lectures and the materials being used.

\subsection{How is information technology integrated in ELT classes in the context of Tunisian higher education?}

Based on the data drawn from the interviews with the two instructors and from the findings of this study, it is clear that IT integration within EFL teaching differs from one instructor to another depending on the instructors' own decisions. Compared to other majors where IT is an obligation, the field of ELT seems to be gradually and slowly witnessing the integration of IT especially from the part of the new generations of EFL instructors who are "tech savvy". Yet, this new wave needs much more support, considerate pedagogical planning and decision makers' readiness and cooperation. In addition, IT integration in ELT classes can overcome some challenges in terms of authenticity of the materials and students' motivation.

\section{Conclusion}

This study aimed at investigating the effects of integrating information technology in language teaching on EFL university students using a mixed method case study approach. The focus of this research was on EFL students' perceptions, motivation, and academic performance in relation to information technologies.

Although the university under the scope of the study has limited resources of IT integration it constitutes a suitable environment which is a good representative example of many public higher education institutions in Tunisia. Limited IT usage and integration did not prevent Tunisian EFL students from having positive attitudes and perceptions toward integrating IT within English language teaching. Actually, Tunisian youths who heavily use social media and different computer-internet technologies in their daily lives also think that IT have a great place in their advanced education as revealed by the survey results in this study. The findings show that IT has a great effect on students' motivation and academic performance. Yet, IT integration in English language teaching needs much more support, effective planning and decision makers' readiness and cooperation as reflected in the interviews with the two instructors. 


\subsection{Recommendations for Implementation}

The findings of this study are expected to be viewed as a basis for future research and investigation in the presence of technology in education. The findings of this study and other similar studies can be very helpful to decision makers in planning and implementing educational reforms mainly in relation to the integration of IT in all aspects of teaching and learning. Furthermore, in spite of the low technology context where the study was undertaken, supporting university administrative and academic staff to integrate more IT resources in all aspects of the teaching and learning process remains highly needed.

\subsection{Limitations of the Study}

First, the findings of this study are not to be generalized to EFL learners in other countries as the study is strictly related to the university under study and to the Tunisian context in general. Second, it should be mentioned that the findings of this study do not pertain to the universities offering scientific majors, as they are hugely different situation regarding infrastructure and information technologies capabilities. Likewise the number of private colleges and universities is steadily rising in Tunisia. These private institutions are known for differing from the norms established by public higher education institutions. Accordingly, the situation in private colleges and universities and the nature of students enrolled in these institutions are hugely different which can generate different findings to a great extent due to different environmental learning infrastructure.

\subsection{Directions for Future Inquiry}

Further research on the topic under study can allow the generalization of findings on wider population. Also, investigating the situation in private colleges and universities regarding the issue of integrating IT in teaching and learning can generate insightful findings that can be a good foundation for comparing the private and public sectors. Further investigation within the Tunisian higher education system is highly needed to provide accurate and effective findings for decision makers to help them implement appropriate educational reforms and changes.

\section{References}

Anggraeni, P. (2007). Audio Lingual Teaching as an Alternative Method in Teaching Speaking. Semarang : Semarang State University.

Bruce, B., \& Hogan, M. (1998). The Disappearance of Technology: Toward an Ecological Model of Literacy. Handbook of literacy and Technology: Transformations in a post-typographic world, (pp.269-281). New York, NY: Greenwood.

Chapelle, C. (2003). English Language Learning and Technology: Lectures on Applied Linguistics in the age of Information and Communication Technology. Philadelphia: John Benjamins Publishing Company.

Daoud, M. (1996). English Language Development in Tunisia. TESOL Quarterly, 30(3), 598-605.

Derbel, F. (2001). EFL teacher preparation, teacher conceptual frame and the task of implementing pedagogical change: Directions for the future teacher education and development in Tunisia. (Unpublished doctoral dissertation). London: University of London.

Hamdy, A. (2007). Survey of ICT and Education in Africa: Tunisia Country Report, ICT in Education in Tunisia. Washington DC: The World Bank. Retrieved from http://www.infodev.org/en/Publication.434.html

Lee, K. W. (2000). English Teachers' Barriers to the Use of Computer-assisted Language Learning. The Internet TESL Journal, VI(12), 1-7. Retrieved from http://iteslj.org/Articles/Lee-CALLbarriers.html

Lewis, G. (2009). Bringing Technology into the Classroom. Oxford: Oxford University Press.

Melliti, M. (2008). The Perceived Value of English: The Case of Tunisian University Students. Manouba, Manouba University. Retrieved from http://www.memoireonline.com/08/11/4642/The-perceived-value-of-english-the-case-oftunisian-university-students.html

Ministry of the Higher Education, T. (2008). Higher Education. Tunis: Ministry of the Higher Education.

Warschaue, M., \& Whittaker, F. (1997). The Internet for English Teaching: Guidelines for Teachers. The Internet TESL Journal, 2(4), 27-33. 